
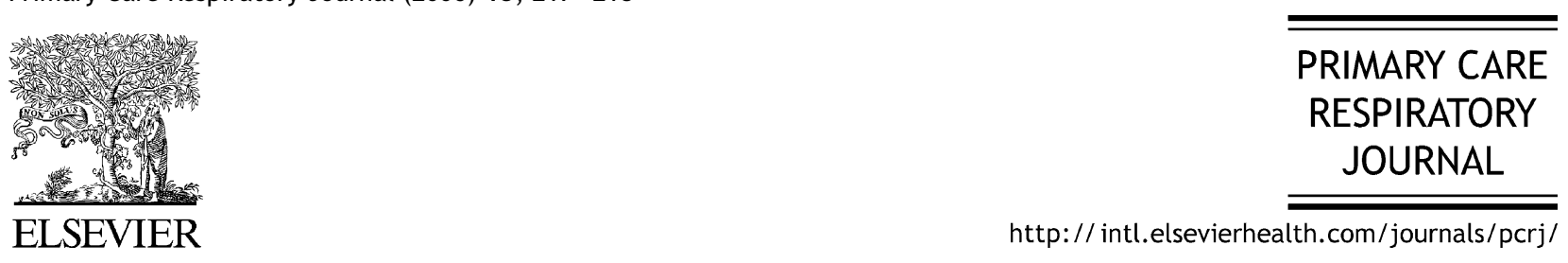

EDITORIAL

\title{
Avian Influenza: preparation not panic
}

In the past, the world has endured recurrent episodes of epidemic diseases that have killed randomly and which have frequently not been amenable to medical intervention. These outbreaks had the potential to sweep away economic and social structures whilst political and administrative functions collapsed, resulting in disorder of a degree not far from anarchy [1]. The last of these was the global disaster wrought by the influenza pandemic of 1918-1919 in which up to 50 million people died [2]. Since then, the late 20th and the 21st centuries have been characterized by a feeling of invulnerability induced by advances in medical science. The rapid identification oi responsible organisms, increaced avaitalbitisy of chemotherapy, more evideitce-bared therapeutic.

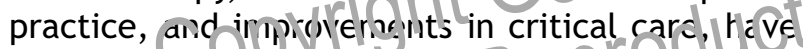
engendered a eeling of proforind domplacency which unfortunately is entirely misplaced.

The current and most likely candidate for a future pandemic is the highly pathogenic H5N1 avian influenza virus, which has an in-hospital mortality of $56 \%$. Confirmed cases now total 216 , with 122 deaths in 10 countries, despite what appears in many cases to have been excellent care $[3,4]$.

The global impact of a full-blown pandemic would be catastrophic. A US Congressional Budget Office report estimates that in the USA alone 200 million would be infected, 90 million would be clinically ill (including 30\% of the workforce), 18-45 million would require outpatient care, and two million are likely to die. From a purely economic point of view, there would be a decrease in Gross Domestic Product of $5 \%$ and a total cost of $\$ 675$ billion.

Medical services would rapidly be overwhelmed even in countries with the most advanced healthcare systems. Intensive care units (ICU's) in particular would be unable to cope with the demand; there are approximately 100,000 ventilators available in the USA relative to the expected requirement of 742,500 . This is unaffordable-even for the richest economy in the world-and excludes consideration of the setting required, and the numbers of sufficiently trained staff needed, to manage these critically ill patients [5]. In South Africa, an example of a developing country, there are approximately 2,560 ventilators in total, and an expectation that ?9,000 would be required: this does nof take into account the current $H \mathrm{IV} / \Delta \mathrm{L}$ : ED cemic, that these patients are ike y to be sicker and will shed virus for longer, and the fart "t'ral: Ifus presently run at capacity and $r=$ equently curn patients away.

Whereas widespread vaccination should be the preventative measure of choice, global vaccine production capacity is only about 900 million $15 \mathrm{mcg}$ doses annually [6]. Unfortunately, a newly tested H5N1vaccine only elicited an adequate immune response following two $90 \mathrm{mcg}$ doses [7]. This means that if newer adjuvant technologies are unsuccessful or unavailable, production capacity can be divided by 12 . This, together with delays in characterization of the antigenic structure of the virus at the onset of a pandemic, means that an adequate supply of specific vaccine is only likely to be available within 3-6 months of the onset of a pandemic.

In the final analysis, hospitals cannot be relied upon to provide care in the event of a pandemic. Primary care practitioners will be the backbone of preparedness planning. In this issue of the Primary Care Respiratory Journal, Lee Gan Goh and Pak Yean Cheong make a timely contribution that will assist practitioners to manage patients appropriately and to evaluate their own levels of preparedness [8]. As detailed in their paper, 
education of the public with regard to respiratory hygiene, and isolation and treatment of cases at home, will be critically important. To this end, primary healthcare practitioners must ensure:

1. That they have an adequate supply of masks both for themselves and their patients. Although masks do not have proven benefit, the incidence of influenza may have decreased in affected countries during the Severe Acute Respiratory Syndrome (SARS) epidemic, possibly due to the widespread wearing of masks [9].

2. That they have familiarized themselves with the diagnosis and management of influenza.

3. That they have a secure source of antivirals for early administration and that there is a system available for rapid distribution.

4. That they develop a simple treatment plan that can be easily distributed to facilitate home treatment. This should detail simple interventions such as oral hydration (including oral rehydration solutions) and nutrition, and control of pyrexia and pain with paracetamol and non-steroidal anti-inflammatory drugs (NSAIDs).

5. That their patients know when someone should be hospitalized.

6. That they know the contact numbers of public health authorities and mortuary services.

These relatively simple necures, rather than

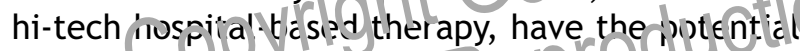
to make the difference otinger) Survival and catastrophe.

\section{References}

[1] Tognotti E. The origins of the health defence system against contagious illness: the strategies of isolation and quarantine in Mediterranean cities from the XIV-XIX centuries. The Adler Museum Bulletin: University of the Witwatersrand South Africa 2005; 31(1): 6-17.

[2] Cunha BA. Influenza:Historical aspects of epidemics and pandemics. Infect Dis Clin North Am 2004;18(1):141-55.

[3] Tran TH, Nguyen TL, Nguyen TD, et al. Avian influenza A (H5N1) in 10 patients in Vietnam. $N$ Engl J Med 2005;350:1179-88.

[4] www.who.int/csr/disease/avian_influenza/country/cases table_2006_05_12/en/index (accessed 18/5/06).

[5] MCNeil DG. Hospitals short on ventilators if bird flu hits. New York Times 2006 March 12.

[6] Poland GA. Vaccines against avian influenza-a race against time. N Engl J Med 2006;354(13):1411-3.

[7] Treanor JJ, Campbell JD, Zangwill KM, Rowe T, Wolff $M$. Safety and immunogenicity of an inactivated subvirion influenza A (H5N1) vaccine. N Engl J Med 2006;354(13): 1343-51.

[8] Goh LG, Cheong PY. The pandemic influenza threat: a review from the primary care perspective. Prim Care Resp J 2006;15(4):222-7.

[9] MCNeil DG. Experts see hurdles to re-using masks in event of a flu pandemic. New York Times 2006, April 28.

\section{Associate Professor Richards*} Associate Professor, Dirgcior, Intensive Care Unit Den arine hof Medicine, University of the Witwaters rand, Johannesburg Hospital, Republic of South Africa

*Tel.: +27 832 668378;

fax: +27 114884675 .

E-mail address: richardsga@medicine.wits.ac.za

Available online at www.sciencedirect.com

SCIENCE DIRECT

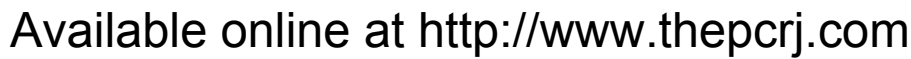

